\title{
A THICK FILM CAPACITIVE TEMPERATURE SENSOR USING BARIUM STRONTIUM TITANATE GLASS FORMULATIONS
}

\author{
S. LEPPÄVUORI, T. HANNULA and A. UUSIMÄKI \\ Department of Electrical Engineering, University of Oulu, Oulu, Finland
}

\begin{abstract}
This paper describes a novel use of thick film techniques to produce a temperature sensor. Ferroelectric materials above their Curie temperature exhibit a dielectric constant which is inversely dependent upon temperature. The measuring range of the sensor can be altered by varying the ratio of the ferroelectric components used $\left(\mathrm{BaTiO}_{3}\right.$ and $\mathrm{SrTiO}_{3}$ ). By using this ceramic together with a glass frit to form a paste, it is possible to employ standard thick film techniques to produce the sensors. Sensors with a composition $\left(\mathrm{Ba}_{0.5} \mathrm{Sr}_{0.5}\right) \mathrm{TiO}_{3}$ were subjected to various temperature and ambient conditions to investigate their temperature performance and stability. The sensors were fundamentally stable and exhibited a capacitance change as large as $65 \%$ of their initial value over a temperature range of $100^{\circ} \mathrm{C}$ and yet the dependence was linear to within $1.5^{\circ} \mathrm{C}$.
\end{abstract}

\section{INTRODUCTION}

The dielectric constant of ferroelectric materials such as barium titanate is strongly dependent upon temperature and increases up to the Curie temperature $\left(T_{c}\right)$, where the material changes from the ferroelectric state to the paraelectric state. Above $T_{c}$, the dielectric constant is inversely dependent upon temperature. This temperature dependence is a disadvantage when a ferroelectric material is used as a capacitor dielectric. However, it has in the past been used to advantage in temperature compensation capacitors. ${ }^{1}$

Another possible use of these dielectrics in the paraelectric state is for temperature sensing. ${ }^{2,3}$ The reactance of a capacitor using such materials is strongly dependent upon temperature and the relationship is virtually linear. Temperature sensors based upon this principle may be manufactured using thick film techniques. By varying the composition of the ceramic component of the thick film paste the properties of the resulting device can be controlled.

This is a new application of thick film materials and temperature sensors of this type offer high linearity and sensitivity, compatibility with hybrid microelectronic production and a competitive price for the device.

\section{PROPERTIES OF BARIUM STRONTIUM TITANATE GLASS FORMULATIONS}

\subsection{Properties of the Ceramic}

Barium titanate $\left(\mathrm{BaTiO}_{3}\right)$ and strontium titanate $\left(\mathrm{SrTiO}_{3}\right)$ are ferroelectric materials which have a perovskite crystal structure. In the ferroelectric state below the Curie temperature they are tetragonal but in the paraelectric state above $T_{c}$ they are cubic. $\mathrm{BaTiO}_{3}$ and $\mathrm{SrTiO}_{3}$ have a complete solid solution and the melting point of this solution increases approximately linearly from that of $\mathrm{BaTiO}_{3}$ $\left(1618^{\circ} \mathrm{C}\right)$ to that of $\mathrm{SrTiO}_{3}\left(2080^{\circ} \mathrm{C}\right){ }^{4}$ Ceramic $\mathrm{BaTiO}_{3}, \mathrm{SrTiO}_{3}$ and solid solutions of the two are produced by solid-state sintering. The dielectric properties of ceramic $\mathrm{BaTiO}_{3}$ are almost independent of the grain size in the paraelectric state, wherein the dielectric constant follows the Curie-Weiss law $\epsilon=C / T-T_{o}$, where $C$ is the Curie constant and $T_{o}$ is the Curie-Weiss temperature, which is within about $10^{\circ} \mathrm{C}$ of the Curie temperature. ${ }^{5}$ The depen-

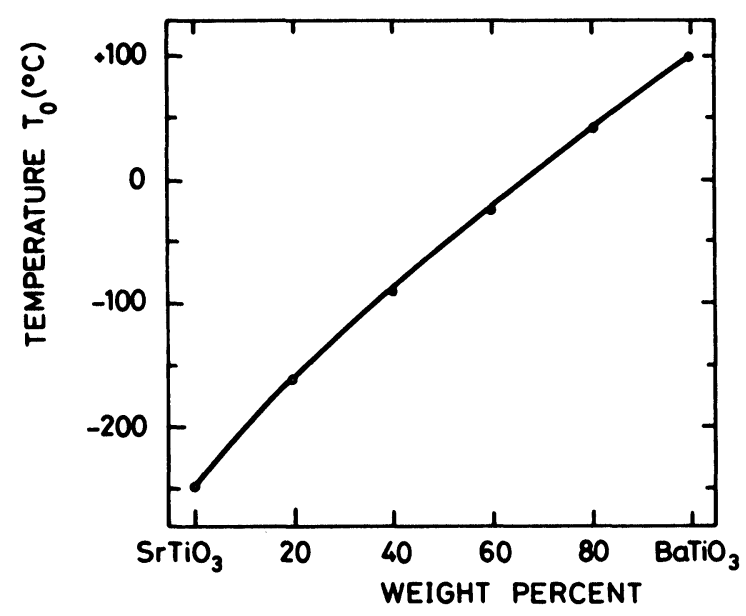

FIGURE 1 The Curie-Weiss temperature $T_{o}$ of $(\mathrm{Ba}, \mathrm{Sr})-$ $\mathrm{TiO}_{3}$ as a function of weight percent of $\mathrm{BaTiO}_{3}$. 
dence of the Curie-Weiss temperature on the $\mathrm{BaTiO}_{3} / \mathrm{SrTiO}_{3}$ ratio is quite linear in the $(\mathrm{Ba}, \mathrm{Sr})$ $\mathrm{TiO}_{3}$-solution (Figure 1).

\subsection{Properties of Ceramic Glass Formulations}

Because of the low sintering temperature of the thick film process solid state sintering of the ceramic is not possible and liquid phase sintering of the glass component of the paste must be used. The thick film dielectric layer has a larger porosity than the ceramic, the volume fraction of which depends mainly upon the volume fraction of the glass component. If the glass frit content is greater than $25 \mathrm{vol} . \%$ then most of the porosity is eliminated. ${ }^{6}$ However, the glass component, together with the porosity, result in the dielectric properties of the mixture being different from those of the pure ceramic. The total value of the dielectric constant $\left(\epsilon_{T}\right)$ can be evaluated from the logarithmic rule, $\log \epsilon_{T}=\Sigma_{i} v_{i} \log \epsilon_{i}$, where $v_{i}$ is the volume fraction and $\epsilon_{i}$ the dielectric constant of each component. ${ }^{7}$

In order to examine the effect of the glass component on the dielectric constant both pressed discs and thick films were used. Figure 2 shows the dielectric constant for various glass frit contents of pressed discs. The plotted point with $0 \%$ glass frit content refers to a disc made by solid state sintering. The theoretical curve shown was calculated from the logarithmic rule assuming no porosity. All other plotted points refer to liquid state sintered samples which have experienced the same temperature profile

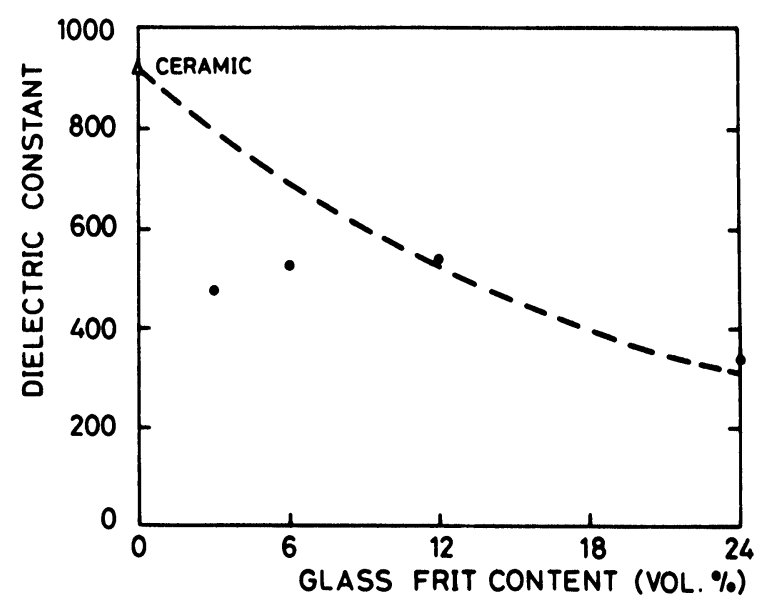

FIGURE 2 The dielectric constant for various glass frit contents of $\left(\mathrm{Ba}_{0.5} \mathrm{Sr}_{0.5}\right) \mathrm{TiO}_{2}$ pressed discs taken at $23^{\circ} \mathrm{C}$. Also shown is the theoretical curve calculated by the logarithmic rule assuming no porosity.
TABLE I

Constants $C, T_{O}, \epsilon_{\max }$ and $T_{C}$ to $\left(\mathrm{Ba}_{0.5} \mathrm{Sr}_{0.5}\right) \mathrm{TiO}_{3}$ with different glass frit contents

\begin{tabular}{lllrl}
\hline $\begin{array}{l}\text { Glass frit } \\
\text { content } \\
(\%)\end{array}$ & $\begin{array}{l}C \\
\left(\mathrm{x} 10^{4}\right)\end{array}$ & $\begin{array}{l}T_{O} \\
\left({ }^{\circ} \mathrm{C}\right)\end{array}$ & $\epsilon_{\max }\left(T_{C}\right)$ & \multicolumn{1}{c}{$T_{C}$} \\
\hline 0 & 8.7 & -70 & 12100 & -65 \\
3 & 3.8 & -75 & 850 & -60 \\
6 & 4.2 & -77 & 1060 & -60 \\
12 & 4.2 & -88 & 920 & -58 \\
24 & 2.6 & -140 & 450 & -56 \\
\hline
\end{tabular}

as the thick films. The differences between the dielectric values of the pressed discs (glass content 3 and 6 vol. \%) and the theoretical curve are caused by porosity. The volume fraction of porosity is about $8 \%$ with a $3 \%$ glass frit content calculated from the logarithmic rule.

Table 1 shows the constants $C$ and $T_{o}$ corresponding to the constants of the Curie-Weiss law and approximated from the measured temperature dependence curves of the reciprocal dielectric constant, the measured maximum dielectric constant $\epsilon\left(T_{c}\right)$ and the Curie temperature of $\left(\mathrm{Ba}_{0.5} \mathrm{Sr}_{0.5}\right)$ $\mathrm{TiO}_{3}$ with different glass frit contents (again, the point at $0 \%$ glass frit content refers to a solid state sintered sample). The results in Table 1 and in Figure 2 show that for the maximum dielectric constant, a glass frit content of between 6 vol. $\%$ and 12 vol. \%, is optimum.

Figure 3 shows the reciprocal dielectric constants

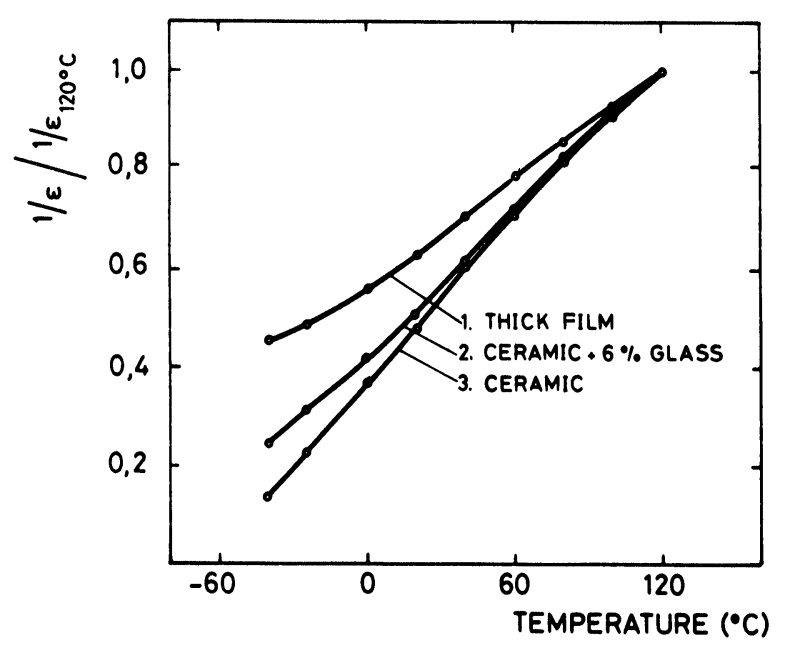

FIGURE 3 The reciprocal dielectric constant (proportional to reactance) normalized to $120^{\circ} \mathrm{C}$ as a function of temperature. 
normalized to a temperature of $120^{\circ} \mathrm{C}$ as a function of temperature for $\left(\mathrm{Ba}_{0.5} \mathrm{Sr}_{0.5}\right) \mathrm{TiO}_{3}$ with a glass frit content of $0 \%$ (curve 3 ) and 6 vol. \% (curve 2). Curve 1 refers to a sample made by thick film techniques. The most important effect is the reduction in the temperature sensitivity of curves 2 and 1 compared with the ceramic curve 3 . Also, it can be seen that curves 2 and 3 have generally a slightly reduced linearity compared with curve 3 and in particular that the thick film material cannot be taken close to the Curie-Weiss temperature of the ceramic without serious non-linearity occurring. Thus it is necessary for good linearity to restrict the operating range of the device to temperatures above $\left(T_{o}+70^{\circ} \mathrm{C}\right)$ i.e. in the case of $(\mathrm{Ba}, \mathrm{Sr}) \mathrm{TiO}_{3}$ sensors, the minimum working temperature is between $-180^{\circ} \mathrm{C}$ to $+170^{\circ} \mathrm{C}$ (Figure 1 ).

\section{PREPARATION OF THE CERAMIC AND THE SENSOR PASTE}

The starting points for the preparation of the ceramic for the temperature sensitive sensor paste are commercial grade barium titanate and strontium titanate powders. After mixing, the powder is homogenised by milling with alcohol or distilled water, pressed into discs and sintered. The material is then milled until the mean particle size is of the order of a few microns. X-ray diffraction analysis indicates that a second sintering process is necessary in order to achieve a satisfactory crystal structure. After the second sintering the material is milled ready for the preparation of the thick film paste. At this stage the mean particle size is still in the order of a few microns. Particles smaller than $1 \mu \mathrm{m}$ are removed by a sedimentation process in an ultrasonic bath.

In the sensor paste a leadborosilicate glass is used for the glass frit and the vehicle consists of ethyl cellulose and butyl carbitol acetate or terpineol. The softening point can be shifted from $600^{\circ} \mathrm{C}$ to $500^{\circ} \mathrm{C}$ and the linear thermal expansion coefficient (TCE) from $4.5 \times 10^{-6} /{ }^{\circ} \mathrm{C}$ to $9.5 \times 10^{-6} /{ }^{\circ} \mathrm{C}$ by varying the composition of the glass $\left(\mathrm{PbO} 60 \ldots 80 \%, \mathrm{SiO}_{2}\right.$ $\left.15 \ldots 5 \%, \mathrm{~B}_{2} \mathrm{O}_{3} 10 \ldots 25 \%\right)$. It is therefore possible to adjust the TCE of the glass so that stresses between the active ceramic powder $\left(\mathrm{TCE}=10 \times 10^{-6} /{ }^{\circ} \mathrm{C}\right)$ and the alumina substrate $\left(\mathrm{TCE}=6.5 \times 10^{-6} /{ }^{\circ} \mathrm{C}\right)$ are minimized.

The glass frit is made by mixing the component oxides and firing in a crucible. The liquid glass is quenched in de-ionised water and the lumps are ground until the particle size is comparable with that

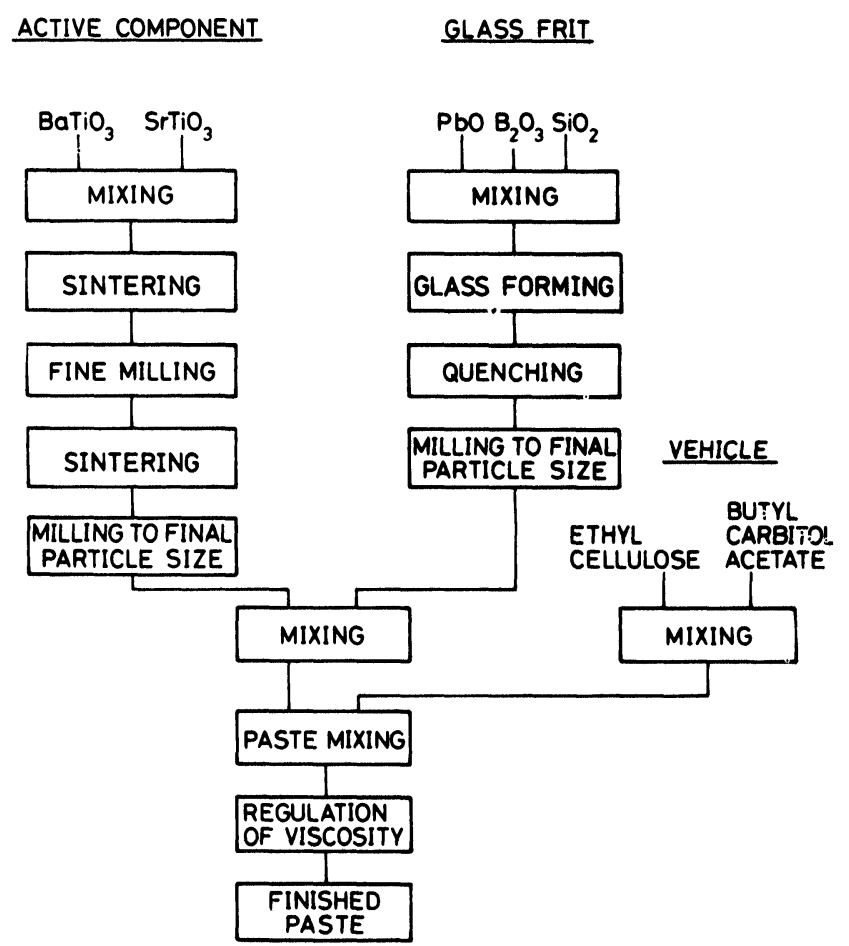

FIGURE 4 Preparation of the sensor paste.

of the final barium strontium titanate powder. The ceramic powder is mixed with the glass frit and the organic vehicle is added. The paste is then thoroughly mixed and the correct viscosity is obtained by varying the amount of organic vehicle. Figure 4 summarises the processes involved in the paste preparation.

Pressed discs were prepared for the examination of the properties of ceramics and the effect of the glass frit. Pure ceramic disc capacitors were taken from the standard process after the second sintering. Discs with some glass frit were pressed and then sintered in the same way as the thick film dielectric materials. Electrodes for the discs were made using $\mathrm{Pd} / \mathrm{Ag}$ thick film conductor paste or by vacuum evaporation.

\section{THICK FILM TEMPERATURE SENSOR}

\subsection{Manufacture and Encapsulation}

The sensors were printed onto Kyocera $96 \% \mathrm{Al}_{2} \mathrm{O}_{3}$ substrates ( 1 in $\times 1$ in $\times 0.025$ in) using Du Pont $\mathrm{Pd}-\mathrm{Ag} 8228$ terminations. The required dielectric thickness of about $40 \mu \mathrm{m}$ was achieved with the use of a 60 mesh screen. The dielectric was then fired at 


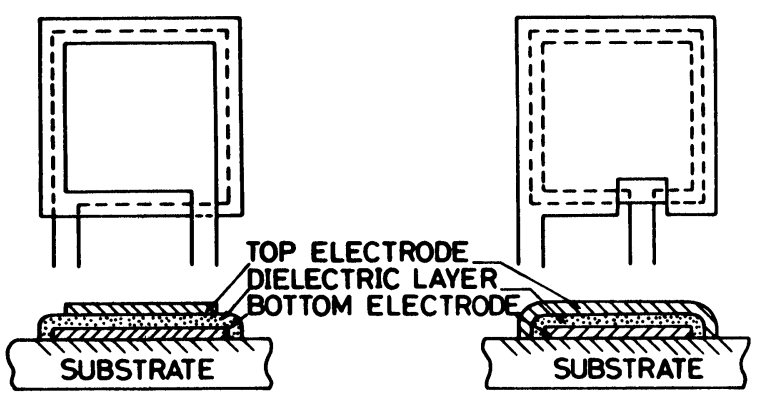

CONSTRUCTION 1

CONSTRUCTION 2

FIGURE 5 Schematic diagrams of two versions of the thick film temperature sensor.

a peak temperature of $900^{\circ} \mathrm{C}$ for about 10 minutes. The terminations were fired separately.

The sensors were manufactured in two different designs (Figure 5). The first structure was encapsulated in a protective coating, ESL 240-SB, which had been double printed. In the second type, where the top electrode covered nearly all the dielectric, encapsulation was achieved by solder-dipping the complete sensor to ensure that the electrode was non-porous. The uncovered part of the dielectric was covered with ESL 240-SB.

A sensor designed for the temperature range $0^{\circ} \mathrm{C}$ to $+100^{\circ} \mathrm{C}$ was selected for the tests to evaluate the properties of the devices. The glass content of the paste was 6 vol. \%, and the active component $\left(\mathrm{Ba}_{0.5} \mathrm{Sr}_{0.5}\right) \mathrm{TiO}_{3}$, the Curie-Weiss temperature of which is about $-70^{\circ} \mathrm{C}$. These selections give a sensor with good sensitivity and linearity (Section 2.2).

\subsection{Properties of the Sensor}

The temperature response of the sensor was measured in a standard environmental chamber at a frequency of $1 \mathrm{kHz}$ (Figure 6). The change in reactance over the temperature range $0^{\circ} \mathrm{C}$ to $+100^{\circ} \mathrm{C}$ was $65 \%$ and the deviation from the best possible straight line relationship between reactance and temperature represents a temperature change of $1.5^{\circ} \mathrm{C}$. Figure 7 shows a block circuit diagram of a CMOS-oscillator using a thick film capacitor sensor. Figure 8 shows the output frequency of the oscillator as a function of temperature.

The thermal time constants of the sensors were determined by measuring the response to a step temperature change from $+23^{\circ} \mathrm{C}$ to $+100^{\circ} \mathrm{C}$. The velocity of the air circulation was $2 \mathrm{~m} / \mathrm{s}$. The response

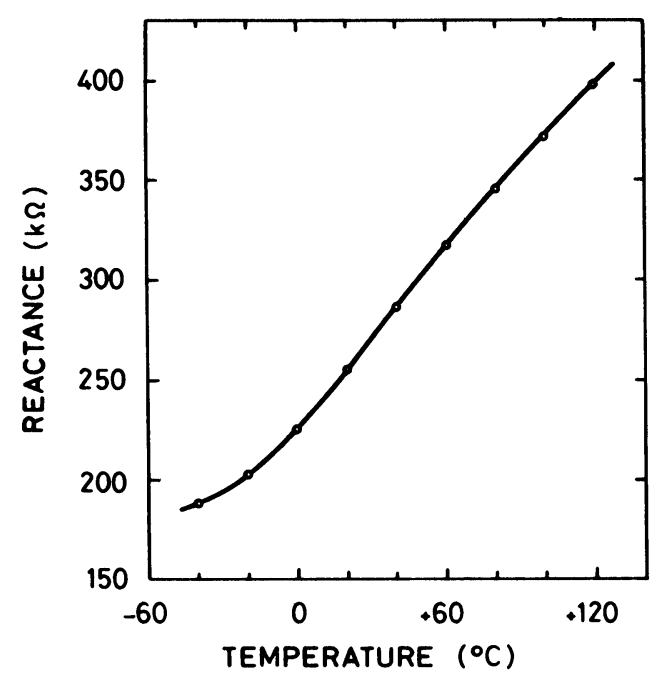

FIGURE 6 The temperature response of a sensor for use over the range $0^{\circ} \mathrm{C}$ to $+100^{\circ} \mathrm{C}$. The measurement frequency is $1 \mathrm{kHz}$ and the area of the capacitor is $10 \mathrm{~mm}^{2}$.

was exponential and the results indicated $95 \%$ of the total change took place in less than 1 minute.

The following tests were performed to examine the stability of the sensors

- Dry heat (IEC 68-2-2), at $+100^{\circ} \mathrm{C}$ for 96 hours.

- Damp heat, steady state (IEC $68-2-3$ ), at $+40^{\circ} \mathrm{C}$ and $93 \% \mathrm{RH}$ for 96 hours.

- Change of temperature (IEC 68-2-14), where each cycle lasted 10 hours of which 4 hours was at $0^{\circ} \mathrm{C}$ and 4 hours at $+100^{\circ} \mathrm{C}$. The number of cycles was 5 and the rate of temperature change, $1.65^{\circ} \mathrm{C} / \mathrm{min}$. The measurements before and after these tests were made at a constant temperature $\left(23^{\circ} \mathrm{C}\right)$ and at a frequency of $1 \mathrm{kHz}$.

The maximum deviation from the starting values which occurred in these tests represents $1.1^{\circ} \mathrm{C}$ to $1.8^{\circ} \mathrm{C}$ uncertainty of measurement which can be improved by improving the encapsulation.

Table II summarizes the properties of the thick film sensor.

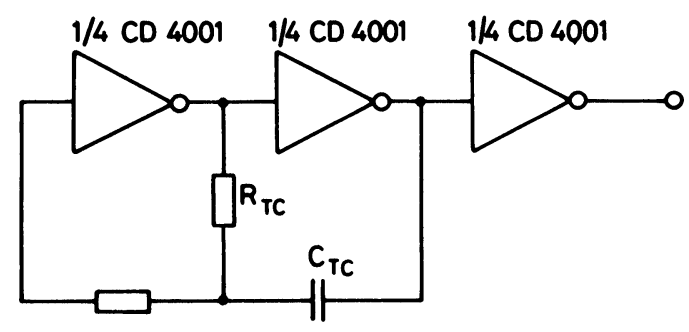

FIGURE 7 The block diagram of a CMOS-oscillator using a thick film capacitive sensor $\left(C_{T C}\right)$. 


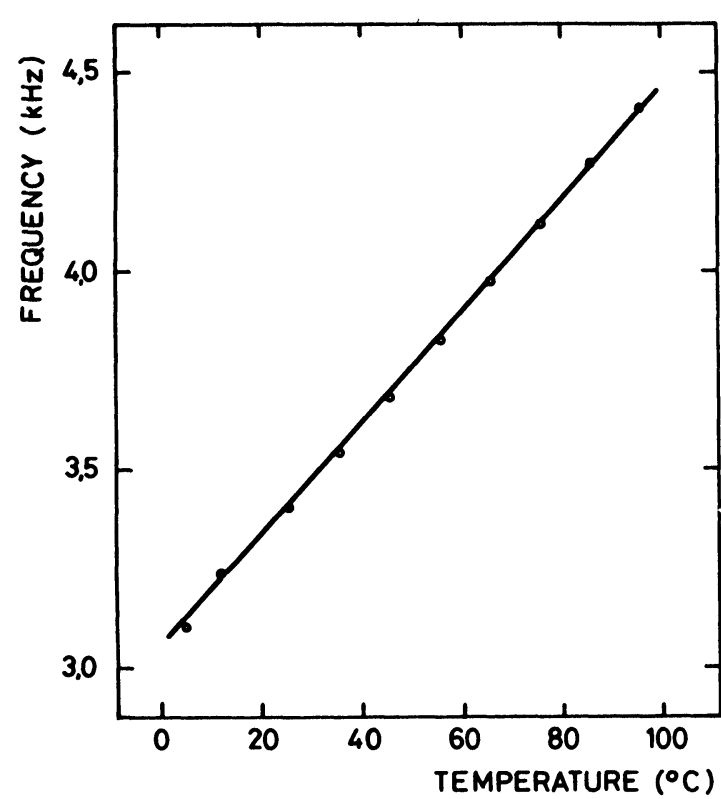

FIGURE 8 The output frequency of the oscillator (Figure 7) as a function of temperature.

\section{CONCLUSIONS}

The thick film capacitive temperature sensor described in this paper can be used over a temperature range of $100^{\circ} \mathrm{C}$. The maximum change in the reactance of the sensor is $65 \%$, the uncertainty of measurement due to non-linearity is $1.5^{\circ} \mathrm{C}$ and the instability is less than $2^{\circ} \mathrm{C}$. The minimum temperature of the sensor can be varied between $-180^{\circ} \mathrm{C}$ and $+170^{\circ} \mathrm{C}$ by adjusting the composition of the sensing material.
The stability tests indicated that the device was stable providing good encapsulation was used. Because they were used at temperatures in excess of the Curie temperature there were no problems encountered with the long term instability normally associated with ferroelectric materials.

This new type of sensor which has been manufactured using standard thick film techniques can be used either as a discrete sensor or alternatively integrated with an oscillator to make a hybrid transducer, the output frequency of which is proportional to temperature. Calibration and instrumentation of this kind of transudcer is simple and because the measurements are made using a.c. there are no errors due to contact resistance or potentials.

\section{ACKNOWLEDGEMENTS}

The authors wish to thank the Tauno Tonning Foundation and the Foundation of Technology in Finland for their financial suppport.

TABLE II

Properties of the sensor

\begin{tabular}{lll}
\hline & Construction 1 & Construction 2 \\
\hline $\begin{array}{lll}\text { Protective coating } \\
\text { Change in reactance } \\
\left(0^{\circ} \mathrm{C} \text { to }+100^{\circ} \mathrm{C}\right)\end{array}$ & ESL 240 -SB & $\begin{array}{l}\text { Solder }(2 \% \mathrm{Ag}) \\
65 \%\end{array}$ \\
$\begin{array}{c}\text { Non-linearity } \\
\left(0^{\circ} \mathrm{C} \text { to }+100^{\circ} \mathrm{C}\right)\end{array}$ & $\pm 1.5 \%$ & $65 \%$ \\
$\begin{array}{c}\text { Instability } \\
(\text { Max. changes in environ. tests) }\end{array}$ & $-0.4 \ldots+1,1 \%$ & $-0.6 \% \ldots 1.8 \%$ \\
$\begin{array}{c}\text { Thermal time constant } \\
\left(10 \mathrm{~mm}^{2} \text { capacitor }\right)\end{array}$ & $19 \mathrm{~s}$ & $14.5 \mathrm{~s}$ \\
$\begin{array}{c}\text { Capacitance per unit area } \\
\left(1 \mathrm{kHz},+23^{\circ} \mathrm{C}\right)\end{array}$ & $65 \mathrm{pF} / \mathrm{mm}^{2}$ & $65 \mathrm{pF} / \mathrm{mm}^{2}$ \\
$\begin{array}{c}\text { Dissipation factor } \\
\left(1 \mathrm{kHz},+23^{\circ} \mathrm{C}\right)\end{array}$ & $0.6 \%$ & $0.6 \%$ \\
\hline
\end{tabular}

1. R. A. Delaney and H. D. Kaiser, "Multiple-Curie-Point Capacitor Dielectrics." IBM Journal, 11, 501 (1967).

2. S. Leppävuori, P. Niemela and A. Uusimäki, "A capacitive thermal sensor using high $\mathrm{K}$ dielectric pastes with negative temperature coefficient." Proc. INTERNEPCON, 101 (1977), Brighton.

3. S. Leppävuori and P. Niemela, "A thick film capacitive temperature sensor." Proc. Electron. Components Conf. IEEE, 47 (1978).

4. E. M. Levin et al. Phase Diagrams for Ceramists (The American Ceramic Society, Columbus, 1964) p. 195. 
5. K. Kinoshita and A. Yamaji, "Grain-size effects on dielectric properties in barium titanate." J. App. Phys. 47, 371 (1976).
6. H. Nester and D. Mason, "Thick Film Capacitors." Proc. Electron. Components Conf. IEEE, 233 (1968).

7. W. D. Kingery, Introduction to Ceramics (John Wiley \& Sons, New York, 1960) Chap. 20, p. 720. 

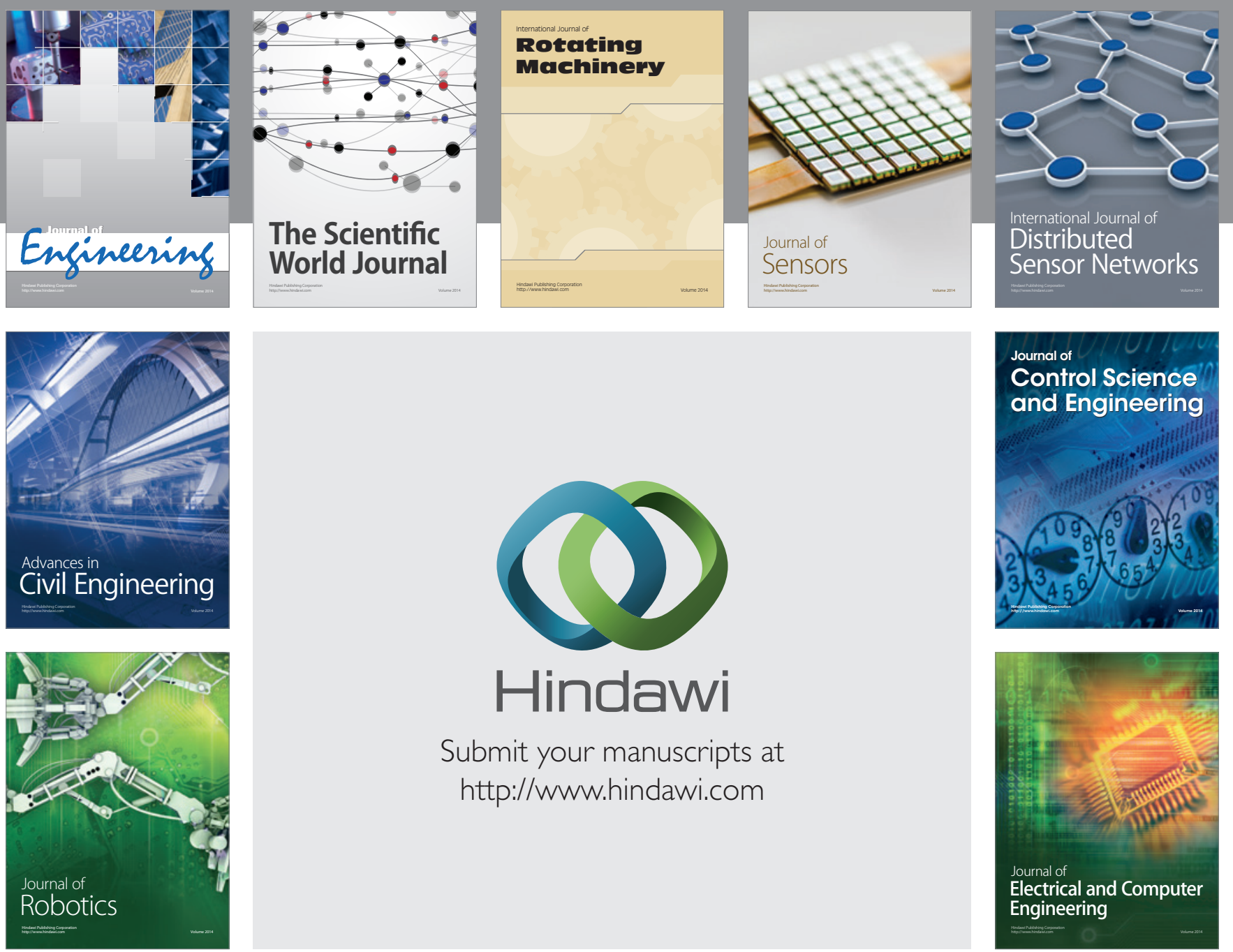

Submit your manuscripts at

http://www.hindawi.com
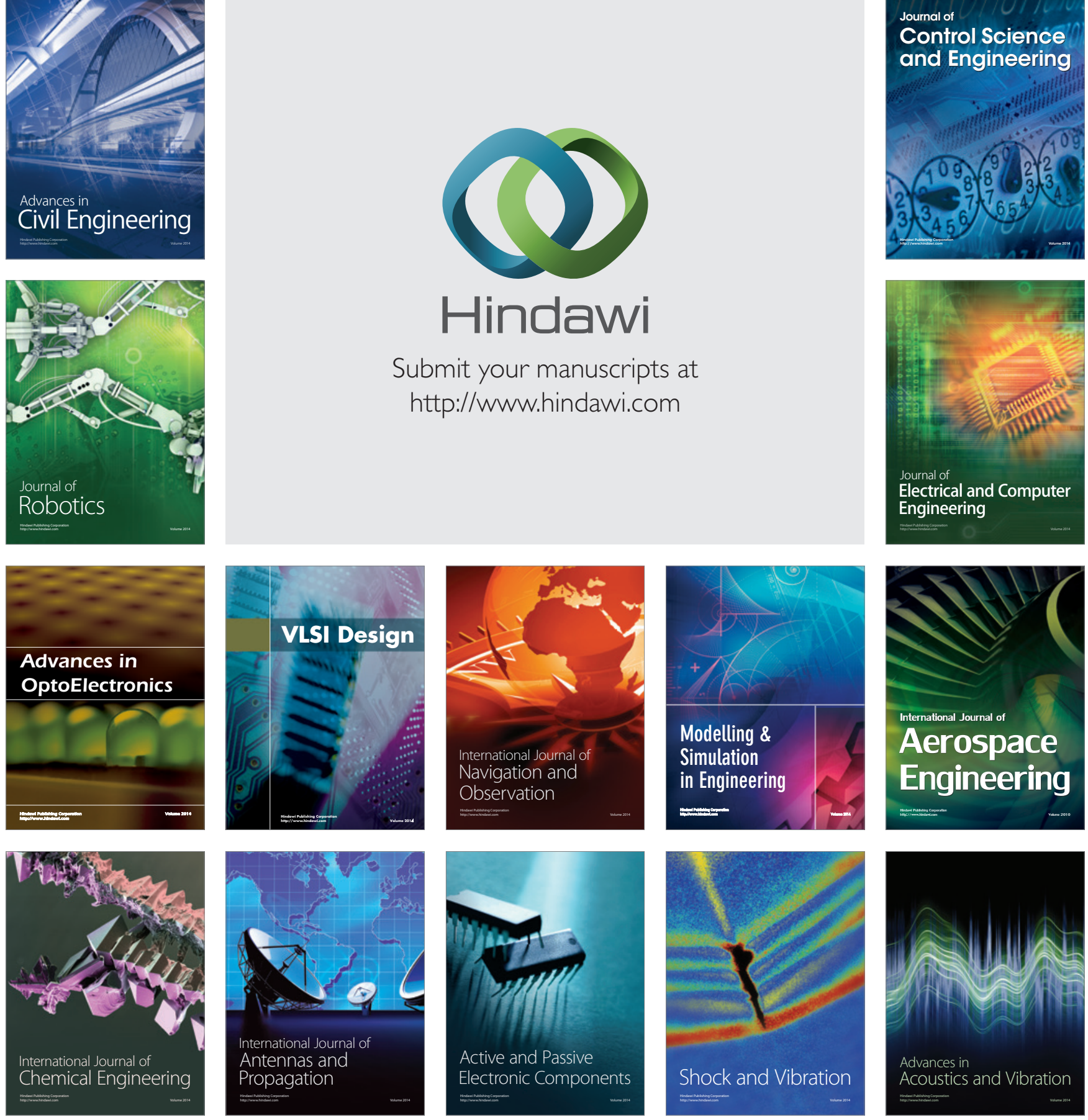